\title{
Postoperative hemorrhage in an elderly patient with a glioblastoma multiform and a calcified chronic subdural hematoma
}

\author{
Jun Cai ${ }^{1,2,3}$, Yanting Zhang ${ }^{1,2}$, Xiaoxin Bai ${ }^{1,2}$, Shaoxue Li ${ }^{1,2}$, Jinhua Chen ${ }^{1,2}$, Ruicong Chen ${ }^{1,2}$, Hao Lin ${ }^{1,2}$ \\ and Shengping Huang ${ }^{1,2^{*}}$
}

\begin{abstract}
Background: Cases with brain tumor and subdural hematoma are rare; surgical management of the elderly patients with a glioblastoma multiform (GBM) and a chronic subdural hematoma (CSDH) can be intractable.

Case description: We report a 77-year-old patient, who had a left front lobe GBM and a giant, calcified, left frontoparietaloccipitotemporal CSDH. The patient recovered well from anesthesia after removal of the GBM and $\mathrm{CSDH}$. However, the patient developed severe hemiplegia and aphasia because of the in-situ hemorrhage 1 day later. Laboratory tests indicated disseminated intravascular coagulation (DIC) leading to the postoperative hemorrhage. The patient was left with hemiparesis and alalia after the in-situ hematoma evacuation.

Conclusions: We presume elderly patients have a higher incidence of postoperative hemorrhage in residual intracranial cavity owing to higher possibility to get DIC. A less aggressive surgical management could be a more appropriate choice.
\end{abstract}

Keywords: Chronic subdural hematoma, Disseminated intravascular coagulation, Glioblastoma multiform

\section{Background}

Brain tumors and subdural hematomas are the most common intracranial lesions suffered by the elderly [1]. However, cases with both these two devastating maladies are infrequent. In addition, there are few data on the complications of management of elderly patients with brain tumors and chronic subdural hematomas. The surgical management of these cases can be problematic.

\section{Case presentation}

A 77-year-old Chinese man was admitted to our hospital with a history of 2 weeks of hypomnesis and mental deterioration. Physical examination was unremarkable. He was diagnosed by computed tomography $(\mathrm{CT})$ and magnetic resonance imaging (MRI) with a glioblastoma multiform

\footnotetext{
* Correspondence: huangsp_gdhtcm@163.com

'Department of Neurosurgery, Guangdong Provincial Hospital of Traditional Chinese Medicine (Affiliated Hospital at Guangzhou Higher Education Mega Center), 55 West Inner Circle Road, Guangzhou 510006, China

${ }^{2}$ The Second Institute of Clinical Medicine, Guangzhou University of Chinese Medicine, Guangzhou 510120, China

Full list of author information is available at the end of the article
}

(GBM) located in the left front lobe as well as a chronic subdural hematoma (CSDH) located in the left frontoparietaloccipitotemporal intracranial cavity (Figure 1a-d). A specific craniotomy was performed; the GBM was resected followed by evacuation of the giant and calcified CSDH (Figure 2a-d). The patient recoverexd from anesthesia well and no new neurological deficit was found after resuscitation. The next morning, the patient developed severe hemiplegia and aphasia due to the in-situ hemorrhage (Figure 1e-f). Postoperative laboratory work-up revealed there was a reduction of fibrinogen $(0.69 \mathrm{~g} / \mathrm{L}$; normal: $2-4$ $\mathrm{g} / \mathrm{L})$ and a huge increase of d-dimers $(29,750 \mu \mathrm{g} / \mathrm{L}$; normal: 0-500 $\mu \mathrm{g} / \mathrm{L}$ ), with platelet count, prothrombin time, and activated partial thromboplastin time all within normal limits. After correction of coagulopathy, secondary craniotomy was performed for the intracranial hematomas evacuation. The patient was left with hemiparesis and alalia after the second operation (Figure 1g-h) and discharged to take extensive neurological rehabilitation.

\section{Biomed Central}

(C) 2014 Cai et al.; licensee BioMed Central Ltd. This is an Open Access article distributed under the terms of the Creative Commons Attribution License (http://creativecommons.org/licenses/by/2.0), which permits unrestricted use, distribution, and reproduction in any medium, provided the original work is properly credited. 

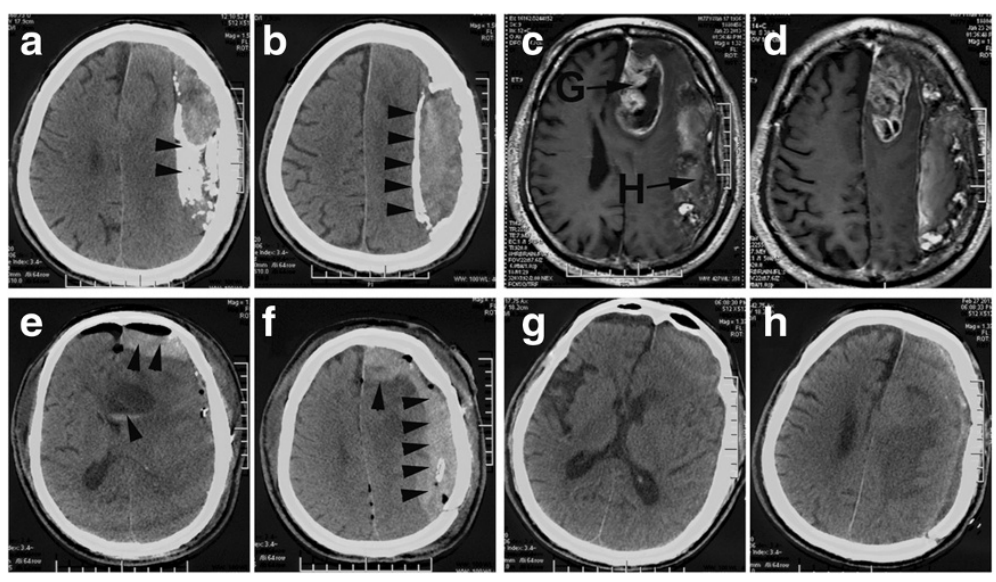

Figure 1 The preoperative and postoperative images of CT and MRI. (a,b) The CT images display the CSDH. The arrowheads point to the calcified membranes. (c, d) The MRI images show the GBM (G) and the CSDH (H). (e, f) The CT images indicate the in-situ hemorrhages after removal of the GBM and CSDH. (g, h)The postoperative CT images of the secondary craniotomy.

\section{Discussion}

GBM is the most common primary malignant brain tumor in geriatric population [1]. Maximal surgical resection is one of the standard treatments for GBM [2]. Craniotomy remains the best option for evacuation of calcified CSDH [3]. Concerning this case, after GBM resection, we expanded the bone flap to thoroughly evacuate the calcified CSDH. No bleeding was found after the surgical procedures.

However, the in-situ hemorrhage was detected 1 day later. Postoperative laboratory analysis indicated the patient was in a state of prior disseminated intravascular coagulation (DIC) at that time. A diagnosis of DIC can be established if laboratory test results show a decreased fibrinogen and increased fibrin degradation products, such as d-dimers [4]. A number of cases are reported that DIC developed during or after removal of brain tumors [5-9], especially in the elderly. Development of DIC during or after craniotomy for brain tumor resection constitutes a very severe complication because nearly half of the patients in the reported cases died postoperatively [9].

There are four subtypes of GBM distinguished by gene expression patterns and clinical characteristics [10]. Studying GBMs using this new subtype classification therefore may accelerate our understanding of GBM pathology. A large sample set might help to determine whether the postoperative DIC correlate with the GBM subtypes, which can be used for optimal therapy.
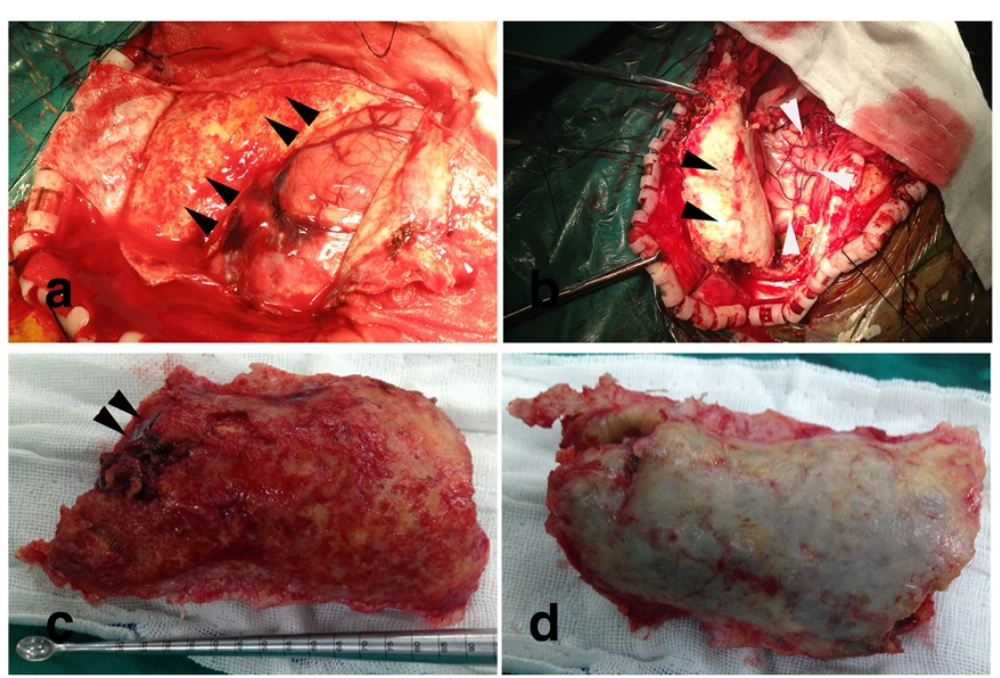

Figure 2 The photographs of the CSDH. (a) The panel displays the intact CSDH. (b) The panel indicates the isolated CSDH. (c) The panel shows the dural surface of the CSDH. Arrowheads point to the inner contents. (d) The panel shows the cortical surface of the CSDH. 


\section{Conclusion}

In summary, we presume elderly patients have a higher incidence of postoperative hemorrhage in residual intracranial cavity owing to higher possibility to get DIC. In the present case, a discreet two-step surgery which is comprised of resection of the GBM and evacuation of the giant and calcified CSDH could be more appropriate.

\section{Consent}

Written informed consent was obtained from the patient and his daughter for publication of this case report and any accompanying images. A copy of the written consent is available for review by the Editor-in-Chief of this journal.

\section{Abbreviations \\ CSDH: Chronic subdural hematoma; CT: Computed tomography; DIC: Disseminated intravascular coagulation; GBM: Glioblastoma multiform; MRI: Magnetic resonance imaging.}

\section{Competing interests}

The authors declare that they have no competing interests.

\section{Authors' contributions}

$J C$ took a part in the surgical and medical management of the patient, and drafted the manuscript. YZ took a part in the medical management of the case and assisted in preparation of the manuscript. XB took a part in the first craniotomy and revised the manuscript. SL and JC participated in the second operation. $\mathrm{RC}$ and $\mathrm{HL}$ participated in the rehabilitation of the patient. SH supervised the whole management of the patient and took a part in the second craniotomy. All authors read and approved the final manuscript.

\section{Authors' information}

$J C, X B, S L, J C$, and $S H$ are neurosurgeons. YZ, who specializes in intensive care therapy, is a neurologist. $\mathrm{RC}$ and $\mathrm{HL}$ are physical therapists.

\section{Acknowledgements}

We thank Dr. Yingbin Li for the imaging data collections and Dr. Lujia Chen for the manuscript revision. This study was supported by the National Natural Science Foundation of China (NSFC No. 81301013) and the Guangdong Natural Science Foundation of China (No. S2013040013591).

\section{Author details}

${ }^{1}$ Department of Neurosurgery, Guangdong Provincial Hospital of Traditional Chinese Medicine (Affiliated Hospital at Guangzhou Higher Education Mega Center), 55 West Inner Circle Road, Guangzhou 510006, China. ${ }^{2}$ The Second Institute of Clinical Medicine, Guangzhou University of Chinese Medicine, Guangzhou 510120, China. ${ }^{3}$ Post-doctoral Research Center of Guangzhou University of Chinese Medicine, Guangzhou 510405, China.

Received: 19 March 2013 Accepted: 7 April 2014

Published: 23 April 2014

\section{References}

1. Roger EP, Butler J, Benzel EC: Neurosurgery in the elderly: brain tumors and subdural hematomas. Clin Geriatr Med 2006, 22:623-644.

2. Anton K, Baehring JM, Mayer T: Glioblastoma multiforme: overview of current treatment and future perspectives. Hematol Oncol Clin North Am 2012, 26:825-853.

3. Imaizumi S, Onuma T, Kameyama M, Naganuma H: Organized chronic subdural hematoma requiring craniotomy-five case reports. Neurol Med Chir (Tokyo) 2001, 41:19-24.

4. Taylor FB Jr, Toh CH, Hoots WK, Wada H, Levi M: Towards definition, clinical and laboratory criteria, and a scoring system for disseminated intravascular coagulation. Thromb Haemost 2001, 86:1327-1330.

5. Berger MM, Ravussin P, Vielle G, Fankhauser H: Life-threatening hemorrhagic diathesis due to disseminated intravascular coagulation during elective brain tumor surgery. J Neurosurg Anesthesiol 1995, 7:26-29.
6. Brecknell JE, McLean CA, Hirano H, Malham GM: Disseminated intravascular coagulation complicating resection of a malignant meningioma. Br J Neurosurg 2006, 20:239-241.

7. Palmer JD, Francis DA, Roath OS, Francis JL, lannotti F: Hyperfibrinolysis during intracranial surgery: effect of high dose aprotinin. J Neurol Neurosurg Psychiatry 1995, 58:104-106.

8. Portugal JR, Alencar A, Brito Lira LC, Carvalho P: Melanotic meningioma complicated by disseminated intravascular coagulation. Surg Neurol 1984, 21:275-281.

9. Velez AM, Friedman WA: Disseminated intravascular coagulation during resection of a meningioma: case report. Neurosurgery 2011, 68:E1165-1169. discussion E1169.

10. Verhaak RG, Hoadley KA, Purdom E, Wang V, Qi Y, Wilkerson MD, Miller CR, Ding L, Golub T, Mesirov JP, Alexe G, Lawrence M, O'Kelly M, Tamayo P, Weir BA, Gabriel S, Winckler W, Gupta S, Jakkula L, Feiler HS, Hodgson JG, James CD, Sarkaria JN, Brennan C, Kahn A, Spellman PT, Wilson RK, Speed TP, Gray JW, Meyerson M, et al: Integrated genomic analysis identifies clinically relevant subtypes of glioblastoma characterized by abnormalities in PDGFRA, IDH1, EGFR, and NF1. Cancer Cell 2010, 17:98-110.

doi:10.1186/1477-7819-12-110

Cite this article as: Cai et al:: Postoperative hemorrhage in an elderly patient with a glioblastoma multiform and a calcified chronic subdural hematoma. World Journal of Surgical Oncology 2014 12:110.

\section{Submit your next manuscript to BioMed Central and take full advantage of:}

- Convenient online submission

- Thorough peer review

- No space constraints or color figure charges

- Immediate publication on acceptance

- Inclusion in PubMed, CAS, Scopus and Google Scholar

- Research which is freely available for redistribution 